\title{
A ordenação de documentos como conteúdo curricular no curso de graduação em Biblioteconomia da UFMG e relato de proposta de disciplina
}

\author{
Camila Mariana Aparecida da Silva ' \\ http:// orcid.org/ 0000-0002-0429-1146 \\ Matheus Aguiar de Carvalho " \\ http:// orcid.org/ 0000-0001-9987-0150
}

Gabriella Braga Andrade Martin' "'

http:// orcid.org/ 0000-0002-3061-2441

Cristina Dotta Ortega'v

http:// orcid.org/ 0000-0002-9735-7676

' Universidade Federal de Minas Gerais, MG, Brasil.

Doutoranda no Programa de Pós-Graduação em Ciência da Informação.

"Universidade Federal de Minas Gerais, MG, Brasil.

Mestrando no Programa de Pós-Graduação em Ciência da Informação.

I"' Universidade Federal de Minas Gerais, MG, Brasil.

Mestranda no Programa de Pós-Graduação em Ciência da I nformação.

IV Universidade Federal de Minas Gerais, MG, Brasil.

Docente na Escola de Ciência da Informação.

http:/ / dx.doi.org/ 10.1590/ 1981-5344/ 4144

Ordenação de documentos é atividade que propõe arranjos para documentos em mobiliários de acordo com atributos definidos como critérios. O número de chamada é uma das principais soluções voltadas à ordenação de documentos no contexto das bibliotecas e como conteúdo trabalhado nos cursos de graduação de Biblioteconomia no Brasil. Nos currículos destes cursos, em geral, a 
ordenação de documentos é alocada de modo parcial nas disciplinas de sistemas de classificação bibliográfica ou nas disciplinas de catalogação. O objetivo do estudo é discutir a ordenação de documentos e o número de chamada como conteúdos de disciplinas obrigatórias do curso de graduação em Biblioteconomia da UFMG, de modo a contextualizar e subsidiar relato de experiência de oferta de disciplina optativa referente à temática, como proposta alternativa ao quadro atual. A metodologia consistiu em pesquisa qualitativa de cunho exploratório em percurso duplo pautado pela abordagem bibliográficadocumental e pela pesquisa-intervenção. Como resultado, observa-se que, na trajetória curricular analisada, a ordenação de documentos foi progressivamente tornandose restrita ao número de chamada, ainda assim, na ausência de abordagem deste modelo como produto complexo e articulado. Ressalta-se a necessidade de ampliar as discussões sobre as transposições didáticas de conteúdos segundo os aportes teóricos que os sustentam.

Palavras-chave: Ordenação de documentos. Número de chamada. Ensino em organização da informação. Escola de Ciência da Informação da UFMG

\section{Shelf arrangement as curricular content in the undergraduate Librarianship course at the Federal University of Minas Gerais and the report of a proposed subject}

Shelf arrangement is the activity that proposes arrangements for documents in furniture according to attributes defined as criteria. Call number is one of the main solutions for arranging documents in the context of libraries and as content developed in undergraduate Librarianship courses in Brazil. In these courses' curricula, shelf arrangement is usually allocated in part within bibliographic classification systems subjects or within 
cataloging subjects. The objective of the study is to discuss shelf arrangement and the call number as contents of core subjects of the Federal University of Minas Gerais undergraduate Librarianship course, in order to contextualize and support the experience of offering elective subjects related to the theme as an alternative proposal to the current framework. The methodology consisted of a qualitative double-track exploratory research based on the bibliographic-documentary approach and the intervention-research. As a result, it is observed that, in the analyzed curricular trajectory, shelf arrangement has progressively become restricted to the call number, however, in the absence of this model's approach as a complex and articulated product. The need to broaden the discussions about the didactic transpositions of contents according to theoretical supports which underpin them is highlighted in the study..

Keywords: Shelf arrangement. Call number. Teaching in information organization. UFMG undergraduate Librarianship course.

Recebido em 06.10.2019 Aceito em 20.02.2020

\section{I ntrodução}

Em sistemas de informação bibliográfica, como bibliotecas, centros de documentação e bases de dados especializadas, efetua-se sobre as coleções um conjunto de “[...] procedimentos que, operados em determinada ordem e encadeamento e, de modo articulado, compõem a organização da informação" (ORTEGA; SILVA; SANTOS, 2016, p. 6). Dentre os procedimentos que integram a organização da informação, em termos gerais, estão incluídas a seleção, a coleta, a representação descritiva e temática, e a ordenação.

Desse conjunto, a ordenação caracteriza-se como o processo em que documentos e metadados de documentos são dispostos segundo certos atributos escolhidos como critérios ordenadores, resultando na proposição de um arranjo, de uma estrutura coerente para essa coleção em relação direta com o espaço de disponibilização e as formas de acesso. Sendo assim, quanto à sua abrangência, o procedimento de ordenação compreende a ordenação de documentos e a ordenação de metadados de documentos. A ordenação de metadados de documentos é realizada em bibliografias impressas, fichas de catálogos de bibliotecas, índices de 
A ordenação de documentos como conteúdo curricular no curso de graduação em Biblioteconomia da UFMG e relato de proposta de disciplina
Camila Mariana Aparecida da Silva; Matheus Aguiar de Carvalho; Gabriella Braga Andrade Martin; Cristina Dotta Ortega

busca de bases de dados e, atualmente, em estruturas hierárquicas de navegação em documentos eletrônicos. Este tipo de ordenação é entendido como a proposição de um arranjo de metadados que atuam como pontos de acesso aos registros dos documentos ou encaminham diretamente aos próprios documentos. Já a ordenação de documentos consiste em uma operação material destinada a arranjar em mobiliários, coleções de documentos de bibliotecas, centros de documentação e outros.

O número de chamada, modelo de origem anglo-americana proposto na segunda metade do século XIX, é, ainda hoje, uma das principais soluções voltadas à ordenação de documentos tanto no contexto de bibliotecas, quanto como conteúdo trabalhado nos cursos de graduação em Biblioteconomia no Brasil. No entanto, o modo de disseminação do número de chamada parece ter contribuído para a criação de lacunas relativas à compreensão dos diferentes modelos e instrumentos voltados à ordenação de documentos, como é o caso do cenário nacional. São poucas as publicações que contemplam a temática no país, sendo parte significativa desta literatura editada até a década de 1970. Trata-se, majoritariamente, de livros traduzidos para a língua portuguesa e de abordagem manualística que priorizam o estudo da classificação bibliográfica ou a composição de notações de autor a partir de tabelas conversoras, como as de Cutter e suas derivações. Nestes livros, não são exploradas a relação da classificação com a ordenação, a abrangência do número de chamada e as possibilidades de ordenação de documentos independente deste modelo. Exceção a este quadro é o trabalho de Pinheiro (2007) sobre os sistemas de localização fixa e as recentes publicações de Caribé $(2016,2019)$ que contemplam discussões sobre o número de chamada e os métodos de ordenação de documentos.

Os estudos desenvolvidos para a elaboração do livro "A ordenação de documentos na atividade bibliotecária", publicado em 2016, e na continuidade da pesquisa com trabalhos como dissertação de mestrado (SILVA, 2016), publicação de artigos (SILVA; ORTEGA, 2017b; SILVA; TOLENTINO; ORTEGA, 2018) e textos apresentados em eventos científicos e profissionais (ORTEGA; SILVA, 2013; ORTEGA, 2015; SILVA; ORTEGA, 2017a; SILVA; TOLENTINO, 2018; SILVA; ORTEGA, 2018b), deixaram bastante evidente a secundarização ou ausência de questões voltadas à ordenação de documentos na literatura relativa à organização da informação e em currículos brasileiros de cursos de graduação em Biblioteconomia. Especialmente, chamou-nos a atenção o quase esquecimento do conteúdo no atual currículo do curso de graduação em Biblioteconomia da Escola de Ciência da Informação ( $E C I)$ da Universidade Federal de Minas Gerais (UFMG). 
A ordenação de documentos como conteúdo curricular no curso de graduação em Biblioteconomia da UFMG e relato de proposta de disciplina
Camila Mariana Aparecida da Silva; Matheus Aguiar de Carvalho; Gabriella Braga Andrade Martin; Cristina Dotta Ortega

No tocante ao curso de graduação em Biblioteconomia em vigor na ECl-UFMG, alguns dos elementos que permitiriam falar em número de chamada (portanto, não todos eles) estão dispersos entre as disciplinas referentes à organização da informação, acentuando a percepção de que a ordenação de documentos permanece pouco discutida e, em grande medida, confundida com os sistemas de classificação bibliográfica. Esta imprecisão é ainda mais problemática quando se adota a denominação de instrumentos específicos em disciplinas, como é o caso das disciplinas "Sistemas de Classificação: CDD" e "Sistemas de Classificação: CDU". Na ementa destas disciplinas, os instrumentos Classificação Decimal de Dewey (CDD) e Classificação Decimal Universal (CDU) são priorizados frente à compreensão da tipologia de instrumentos (sistemas de classificação bibliográfica) a que pertencem, por sua vez, desvinculados dos processos a que respondem.

Assim, o objetivo do estudo consiste na discussão da ordenação de documentos e do número de chamada como conteúdos programáticos de disciplinas obrigatórias do curso de graduação em Biblioteconomia da UFMG, de modo a contextualizar e subsidiar relato de experiência de oferta de disciplina optativa referente à temática, proposta como alternativa ao quadro encontrado.

Como metodologia, realiza-se uma pesquisa qualitativa de cunho exploratório desenvolvida em duplo percurso que se complementa e visa sustentar a proposta: a abordagem bibliográfica-documental (CELLARD, 2014) e a pesquisa-intervenção (DAMIANI et al., 2013).

De um lado, a abordagem bibliográfica-documental é oportunizada pela caracterização dos elementos basilares da ordenação de documentos e do número de chamada, bem como pelo levantamento documental dos programas de disciplinas obrigatórias do curso de graduação em Biblioteconomia da UFMG que abarcam a temática da ordenação de documentos. Quanto à caracterização da ordenação de documentos e do número de chamada, buscou-se por textos que contemplassem ou fossem dedicados ao estudo da temática ou de instrumentos a ela associados. Quanto à análise dos programas de disciplinas do curso, optou-se pelo exame dos conteúdos expressos nas ementas e conteúdos programáticos desde seu início em 1950, que apresentassem tópicos próprios à ordenação de documentos, a partir de vários termos relacionados, a saber: ordenação, número de chamada, sistemas de localização (localização fixa e localização relativa), dados de localização, número do livro, número de Cutter, notação de autor, tabelas de autor, sistemas de classificação, dentre outros. Com este movimento, intentou-se esboçar uma reflexão histórica sobre as mudanças institucionais que nortearam o processo de formação discente quanto a esse conteúdo clássico da área, mas com ênfase na análise da atual versão curricular. 
A ordenação de documentos como conteúdo curricular no curso de graduação em Biblioteconomia da UFMG e relato de proposta de disciplina
Camila Mariana Aparecida da Silva; Matheus Aguiar de Carvalho; Gabriella Braga Andrade Martin; Cristina Dotta Ortega

Por outro lado, a pesquisa intervenção (DAMIANI, 2012; DAMIANI et al., 2013) visa refletir sobre a empiria de uma proposta de ação pedagógica relativa ao oferecimento de disciplinas optativas voltadas à discussão da ordenação de documentos como estratégia provisória para amenização da lacuna identificada. Parte-se do pressuposto, como diz Damiani, de que as intervenções relativas ao processo de ensinoaprendizagem podem conduzir ao aprimoramento de práticas pedagógicas existentes ou à elaboração de novas, produzindo conhecimentos. Assim, a sistematização da proposta de disciplina optativa, incluindo os critérios que orientaram as escolhas, as estratégias didáticas empregadas e as questões suscitadas pelo trabalho, procura refletir sobre a interveniência das práticas de ensino-aprendizagem na configuração do processo educacional em nível superior.

Entende-se que a reflexão sobre o percurso institucional da temática contribui para a elucidação de questões relativas não apenas ao estudo em questão, mas auxilia na compreensão da configuração da estrutura curricular vigente e suas implicações, na medida em que ultrapassa o tema e tangencia outros conteúdos e suas articulações no âmbito da organização da informação. Ademais, o trabalho pauta-se pelo entendimento de que a análise assim circunscrita pode contribuir para que se apreenda a expressão desta temática no que tange às práticas docentes e de pesquisa e, ainda, quanto aos norteamentos que, via de regra, conduzem o exercício profissional.

\section{Conceito de ordenação de documentos e o modelo número de chamada}

A atividade de ordenação compreende o processo pelo qual documentos e metadados de documentos são alocados e relacionados segundo atributos específicos escolhidos como critérios ordenadores, resultando em uma estrutura coerente para a coleção. Assim, quanto à sua abrangência, a atividade de ordenação abarca a ordenação de documentos e a ordenação de metadados de documentos. Neste trabalho, nos ocuparemos essencialmente da ordenação de documentos.

Conforme definição estabelecida por Jouguelet (1997), a ordenação de documentos é uma operação material de arranjo que situa fisicamente os documentos, colocando uns em relação aos outros. Em outras palavras, a ordenação de documentos caracteriza-se como

[...] o processo de arranjo de uma coleção ou de parte de uma coleção de itens documentais, em móveis, como estantes ou arquivos, decorrente de operações baseadas em uma ordem preestabelecida a partir de determinado critério de interesse. (ORTEGA; SILVA; SANTOS, 2016, p. 15). 
A definição do modelo de disposição dos documentos nos mobiliários é guiada pelos objetivos da instituição, considerando a especificidades do público que lhe corresponde, em devida consonância com as características da coleção constituída.

Em sistemas de informação bibliográfica, como bibliotecas e centros de documentação, a ordenação de documentos - embora mais visível não é a única atividade de ordenação realizada: são ordenados os documentos e igualmente os metadados de documentos. Vellucci (1998, p. 192), após revisão de definições do termo metadado, propõe que ele se refere ao dado eletrônico que descreve atributos de um recurso e caracteriza seus relacionamentos, permitindo sua recuperação, identificação e uso, além de realizar seu gerenciamento. Muitos autores reconhecem que o conceito de metadados de um documento corresponde ao do registro catalográfico ou bibliográfico, mas o termo foi adotado para privilegiar o ambiente eletrônico e suas especificidades. Do mesmo modo, o termo recurso passou a ser utilizado para o que denominamos de modo mais genérico, neste artigo, como documento. Assim, a ordenação de metadados de documentos consiste em uma proposição de arranjo de metadados que atuam especificamente como pontos de acesso a documentos (portanto, não incluindo a descrição e os dados administrativos). Como desenvolvido por Ortega, Silva e Santos (2016, p. 12), a ordenação de metadados refere-se à ordem atribuída às entradas das referências de bibliografias e seus índices de acesso, aos cabeçalhos de fichas catalográficas, aos índices das bases de dados de qualquer tipo e aos termos que compõem as hierarquias construídas para navegação e acesso a documentos eletrônicos.

A atividade de ordenação, em sentido amplo, apresenta três funções básicas: modo de leitura, localização dos documentos e gestão da coleção (ORTEGA; SILVA; SANTOS, 2016). O modo de leitura da coleção compreende uma proposta de disposição dos documentos que permita a orientação, exploração e circulação pelo espaço. A função de localização dos documentos possibilita que um documento determinado seja identificado e acessado em uma coleção através da atribuição de um código de localização. A gestão de documentos, por sua vez, refere-se às políticas de seleção e descarte de documentos e ao planejamento dos espaços para sua alocação.

A ordenação de documentos é operacionalizada através de três métodos principais: cronológico, alfabético e classificatório (ORTEGA; SILVA; SANTOS, 2016). O método cronológico expressa a ordenação dos documentos em uma sequência temporal linear, baseando-se em atributos como ordem de entrada na coleção ou ano de publicação. No método alfabético, atributos passíveis de alfabetação, como autor e título, são utilizados para a ordenação dos documentos segundo uma sequência 
A ordenação de documentos como conteúdo curricular no curso de graduação em Biblioteconomia da UFMG e relato de proposta de disciplina
Camila Mariana Aparecida da Silva; Matheus Aguiar de Carvalho; Gabriella Braga Andrade Martin; Cristina Dotta Ortega

linear A-Z. O método classificatório contempla uma estrutura concebida para a organização hierárquica dos atributos dos documentos da coleção em agrupamentos de classes e subclasses. Os atributos definidos podem ser o assunto, a tipologia documental, o idioma, a região geográfica, dentre vários outros, desde que elaborados segundo uma estrutura hierárquica.

O método classificatório remete ao processo de classificação bibliográfica. A classificação, em sentido amplo, significa o processo mental pelo qual coisas, seres ou pensamentos, são reunidos segundo as semelhanças ou diferenças que apresentam (BARBOSA, 1969). A classificação bibliográfica, por sua vez, é a operação intelectual que envolve a identificação de características dos documentos, reunindo os que apresentam características semelhantes e separando os que têm características diferentes (ORTEGA; SILVA; SANTOS, 2016). Nesse sentido, classificar documentos não se refere unicamente ao atributo assunto, porque não se trata de classificar o conteúdo temático dos documentos, mas de ordenar esses documentos segundo as diversas características pertinentes ao objetivo da instituição e das especificidades de seu público.

Não obstante a diversidade de estruturas hierárquicas propícias para fins de ordenação de documentos, os tradicionais sistemas de classificação bibliográfica, como CDD e CDU, firmaram-se como os principais instrumentos empregados pelo método classificatório em diversos países, dentre eles, o Brasil. Entende-se, como Satija (1990), que o trabalho com os sistemas de classificação bibliográfica sem uma interlocução com a ordenação de documentos confere função restritiva e vaga a estes sistemas, pois sua história não é considerada. Ademais, torna-se necessário explorar, como pondera Verón (1989), como a conjugação da espacialização com a classificação bibliográfica pode intervir na estrutura da segunda e, ainda, o fato de que toda disposição de coleções em dado espaço pressupõe uma hipótese sobre o usuário, seus interesses e expectativas.

Quanto ao modo de alocação dos documentos, dois sistemas distintos foram criados: o sistema de localização fixa e o sistema de localização relativa. Nos sistemas de localização fixa, segundo Pinheiro (2007), os documentos são ordenados tendo em vista a determinação de um lugar definitivo para seu posicionamento. Atributos como tamanho, data de publicação, ordem de entrada ou suporte balizam a elaboração de tais sistemas, que são propícios para atender contextos em que a economia de espaço ou a conservação da materialidade dos documentos se colocam como objetivos predominantes. Coleções ordenadas sob localização fixa apresentam, via de regra, interdição ao acesso livre dos usuários. 
A ordenação de documentos como conteúdo curricular no curso de graduação em Biblioteconomia da UFMG e relato de proposta de disciplina
Camila Mariana Aparecida da Silva; Matheus Aguiar de Carvalho; Gabriella Braga Andrade Martin; Cristina Dotta Ortega

Nos sistemas de localização relativa, ao contrário, a posição do documento no arranjo é feita tendo em vista sua relação com os demais documentos e não há um lugar definitivo para o documento. Os sistemas de localização relativa são elaborados de modo a permitir frequentes alterações no posicionamento dos documentos decorrentes da incorporação de novos itens, sem alteração da estrutura concretizada (MANN, 1962). Em tais sistemas, conforme Ortega, Silva e Santos (2016), os agrupamentos de documentos são estruturados em classes e subclasses mais ou menos exaustivas e que favoreçam a função comunicativa do arranjo. Para as subclasses, estabelecem-se critérios secundários que determinam o modo como os documentos são dispostos dentro das classes. A localização relativa possibilita a navegação espacial, sendo, por isso, mais adequada para sistemas de informação bibliográfica nos quais há livre acesso às estantes.

Na tradição anglo-americana, o número de chamada (call number ou shelf location) ocupa lugar de destaque na instrumentalização de sistemas de localização relativa. O número de chamada é um conjunto de símbolos construído a partir de sistemas e tabelas representativos do documento, permitindo o agrupamento de documentos semelhantes de acordo com um critério escolhido, assim como sua individualização na coleção. 0 número de chamada apresenta-se como "um código aposto em lugar visível" no documento e, também, "em seu registro bibliográfico, de forma a localizá-lo fisicamente em acervo específico" (MEY; SILVEIRA, 2009, p. 174).

Os princípios e a estrutura do número de chamada foram sistematizados pelo bibliotecário indiano S. R. Ranganathan aproximadamente em 1930. O modelo explicitado pelo autor estabelecia a ligação entre três elementos, na seguinte sequência: o número de coleção (collection number), o número de classe (class number) e o número do livro (book number) (RANGANATHAN, 1967).

O número de coleção é um elemento de uso facultativo no número de chamada, que busca apartar parcelas da coleção do agrupamento geral. Pode representar, também, a instituição onde se encontra o documento, em contextos nos quais a coleção é composta por acervos alocados em espaços distintos. O número de classe indica a classe à qual o documento faz parte quanto a certo atributo levado em conta para este fim, objetivando reunir nas estantes, documentos com características semelhantes. O número do livro diz respeito a uma combinação de atributos documentais que são empregados para distinguir e individualizar documentos agrupados sob um mesmo número de classe. Para a elaboração do número do livro com base em critérios alfabéticos, como a autoria e o título, tornou-se bastante frequente, no contexto brasileiro, a composição da notação de autor com o uso de tabelas como a Cutter 
A ordenação de documentos como conteúdo curricular no curso de graduação em Biblioteconomia da UFMG e relato de proposta de disciplina
Camila Mariana Aparecida da Silva; Matheus Aguiar de Carvalho; Gabriella Braga Andrade Martin; Cristina Dotta Ortega

(1908), a Cutter-Sanborn (1962) e a PHA (PRADO, 1984), esta última elaborada para sobrenomes comuns na língua portuguesa. A fim de distinguir documentos em que o número de classe e a notação de autor são idênticos, utiliza-se a marca da obra, sendo comum o emprego de atributos como ano de publicação, ordem de entrada, título, número de edição, dentre outros.

Os elementos do número de chamada estavam presentes nas propostas de bibliotecários como Schwartz, Cutter, Dewey, Brown e Bliss, realizadas entre meados do século XIX e início do século XX. A formulação do modelo de número de chamada para viabilizar sistemas de localização relativa consolidou-se, no entanto, a partir dos debates ocorridos especialmente nos anos que se seguiram à publicação da CDD por Melvil Dewey e aos primeiros volumes do Library Journal, ambos publicados a partir de 1876. Ainda que não apresentassem a concatenação linear explicitada por Ranganathan na década de 1930, todos aqueles autores afirmavam ser necessário adicionar à notação extraída do esquema classificatório elementos que auxiliassem na identificação singular de cada documento no conjunto da coleção. O número de chamada é modelo, cuja fórmula explicitada por Ranganathan quase 60 anos depois de seus primeiros debates, configura, ainda hoje, a principal estratégia adotada para a ordenação de documentos em coleções de livre acesso às estantes.

\section{A ordenação de documentos no curso de graduação em Biblioteconomia da UFMG: percurso curricular e configuração atual}

A trajetória da ordenação de documentos e, particularmente, do número de chamada nos programas das disciplinas obrigatórias do curso de graduação em Biblioteconomia da ECI/UFMG fornece elementos que permitem mapear a presença e a abordagem do tema. Ademais, auxiliam na compreensão de sua atual configuração e correlação com outros conteúdos obrigatórios de organização da informação. Para fins desta análise, no âmbito geral, foram utilizados artigos nos quais se discutiam as versões curriculares que vigoraram na Escola (ASSUNÇÃO; FIUZA, 1974; CESARINO; VIANNA, 1990). No âmbito específico, concernente à temática da ordenação de documentos, foram levantadas as respectivas disciplinas obrigatórias em que figuraram conteúdos associados à temática. No período que compreende os anos entre 1950 e 1964, foram examinadas as descrições dos conteúdos ministrados que constavam nos diários de classe dos professores. Do ano de 1965 até a versão curricular vigente, o estudo foi feito tendo por base os programas das disciplinas.

No percurso curricular, as questões referentes à ordenação de documentos estiveram distribuídas conjuntamente aos conteúdos de 
A ordenação de documentos como conteúdo curricular no curso de graduação em Biblioteconomia da UFMG e relato de proposta de disciplina
Camila Mariana Aparecida da Silva; Matheus Aguiar de Carvalho; Gabriella Braga Andrade Martin; Cristina Dotta Ortega

classificação e de catalogação, cuja centralidade na área remete à sua institucionalização acadêmica e científica.

Nas primeiras décadas do curso, de 1950 até a metade da década de 1970, as disciplinas referentes à classificação agruparam os conteúdos sobre a ordenação de documentos. Nesse período, o processo de ordenação era discutido em consideração às suas diversas formas de concepção frente a uma coleção de documentos. Enfatizavam-se as diferentes estratégias que poderiam nortear a composição de arranjos, fossem elas os tipos de público ou os atributos documentais como autoria, assunto, tamanho ou ordem de entrada na instituição. Também eram abordados os sistemas de localização fixa e relativa de documentos como tópicos pertinentes ao âmbito das disciplinas.

No que concerne aos sistemas de classificação bibliográfica, as propostas destacavam-se pela diversidade de instrumentos contemplados. Embora, via de regra, o enfoque tenha sido dado à CDD e à CDU, o ensino não se restringia a estes sistemas, sendo trabalhadas a Classificação dos Livreiros de Jacques Charles Brunet, a Classificação Expansiva de Cutter, a Library of Congress Classification (LCC), a Classificação Bibliográfica de Henry Bliss e a Colon Classification (CC) de Ranganathan.

Para a elaboração do número do livro, eram contempladas as tabelas de codificação dos sobrenomes de autores, como a tabela de Cutter, de 1880, Cutter-Sanborn, de 1896 e a tabela PHA, de 1964, criada por Heloísa de Almeida Prado especificamente para a codificação de sobrenomes brasileiros. Nos programas, encontram-se também alusões à tabela de Biscoe, de 1885, concebida para a codificação de anos e cuja utilização era indicada quando se queria manter um arranjo cronológico dentro das classes, considerando-se, prioritariamente, o ano de publicação dos documentos.

A partir de metade da década de 1970, a abordagem à ordenação de documentos foi reduzida, tanto em relação aos conteúdos pertinentes ao processo, quanto àqueles referentes à constituição do modelo do número de chamada e dos instrumentos que respondem a ele. Os conteúdos sobre ordenação de documentos foram reunidos em disciplina intitulada "Classificação e Catalogação" e, diferentemente do quadro anterior, o processo era explorado a partir do número de chamada que, por sua vez, era abordado apenas pelo estudo das tabelas de CutterSanborn e de PHA. A classificação era desenvolvida em torno dos sistemas de classificação bibliográfica, com enfoque para a CDU e o catálogo sistemático, e, embora houvesse alusão às classificações facetadas, enumerativas e especializadas, os instrumentos correspondentes a elas foram mencionados em poucas versões dos programas.

A mudança curricular de 1985 e as reformas em 1990 redistribuíram os conteúdos de organização da informação nas disciplinas "Tratamento 
A ordenação de documentos como conteúdo curricular no curso de graduação em Biblioteconomia da UFMG e relato de proposta de disciplina
Camila Mariana Aparecida da Silva; Matheus Aguiar de Carvalho; Gabriella Braga Andrade Martin; Cristina Dotta Ortega

da Informação I", “Teoria da Classificação e Indexação" e "Tratamento da Informação II".

O número de chamada foi inicialmente ministrado na disciplina "Tratamento da Informação II". Nela eram contemplados a análise de assunto e instrumentos como tesauros e sistemas de classificação bibliográfica, mas também o tópico chamado "Elaboração de Catálogos", em que constavam: estrutura e organização, número de chamada e os tipos de catálogos dicionário e sistemático. A partir de 1994, o número de chamada foi migrado para a disciplina "Tratamento da Informação I", voltada ao ensino da descrição bibliográfica e dos pontos de acesso em livros, catálogos de bibliotecas e bibliografias. Na disciplina anterior, o tópico "Elaboração de Catálogos" permaneceu o mesmo, embora sem o item número de chamada, enquanto, na disciplina seguinte, incorporou-se ao programa um tópico próprio, sem divisões, chamado Número de Chamada. Somente a partir de 1996, criou-se um tópico chamado "Partes da Catalogação", composto por: descrição bibliográfica, pontos de acesso e dados de localização. Embora o termo "dados de localização" possa supor ampliação do escopo do modelo número de chamada, anteriormente adotado, para outros modelos, não há indicação que sinalize para esta ampliação. Esta expressão converge com a adotada por Mey (1995) em seu livro "Introdução à Catalogação", sendo a obra uma referência constante nos programas. Neste livro, a autora contempla unicamente o número de chamada, considerando apenas a função de localização de um documento em uma coleção, sem discutir, por exemplo, os sistemas de localização fixa ou o emprego de atributos variados para fins de ordenação, como é recorrente na literatura sobre esse modelo.

Quanto aos sistemas de classificação bibliográfica, o enfoque se desenvolveu em torno da CDD e da CDU, mas seus usos, conforme análise dos programas, não nos indica que tenham sido abordadas quanto ao estabelecimento de notações classificatórias como subsídio ao arranjo de coleções. Além disso, tanto na disciplina "Teoria da Classificação e Indexação" quanto na disciplina "Tratamento da Informação II", há um conteúdo nos programas que expressa entendimento de sistemas de classificação bibliográfica como linguagens de indexação, haja vista serem listados, sob esta categoria de instrumentos, junto às listas de cabeçalhos de assunto e tesauros.

Percebe-se, portanto, que, no período de meados dos anos 1980 até fins dos anos 1990, em termos de ordenação de documentos, as formas de agrupamento dos conteúdos foram mantidas em relação ao currículo anterior: a atividade permaneceu circunscrita ao número de chamada sem maiores especificações quanto aos modos como essa abordagem ocorria e sem relações explicitadas com a classificação e a catalogação. Diferentemente do período anterior, no entanto, observa-se indistinção 
A ordenação de documentos como conteúdo curricular no curso de graduação em Biblioteconomia da UFMG e relato de proposta de disciplina
Camila Mariana Aparecida da Silva; Matheus Aguiar de Carvalho; Gabriella Braga Andrade Martin; Cristina Dotta Ortega

conceitual entre indexação e classificação e migração do conteúdo número de chamada de disciplinas que contemplavam os sistemas de classificação bibliográfica para disciplinas voltadas ao processo de catalogação.

No currículo de 1998, um conjunto de disciplinas sequenciais "Tratamento Temático da Informação I, II, III, IV e V" - passou a cobrir os conteúdos de organização da informação. O número de chamada manteve-se exclusivamente na disciplina relativa à catalogação: Tratamento da Informação I. Entretanto, o termo "número de chamada" era apresentado nas ementas, enquanto nos programas constava "Dados de localização", já adotado nos programas desde 1996, mas agora registrado como tópico próprio e sem divisões. Observa-se que houve inconsistência entre ementa e programa, já que o termo "dados de localização" é mais genérico que número de chamada, embora coubesse à ementa a apresentação de conteúdos gerais. No programa de 2006, o número de chamada voltou a ser discriminado como subtópico: reunidos no tópico "Dados de localização", constavam número de chamada, número de tombo e numeração padronizada ISBN, ISSN e outros. Este agrupamento torna difícil inferir os sentidos atribuídos a estes elementos diversos, haja vista o fato de cada um deles responder a funções distintas.

Em relação à classificação bibliográfica, as disciplinas mantiveram-se restritas aos estudos da CDD e CDU, fazendo menção em alguns anos à Colon Classification. Como exemplo disto, a CDD, no programa de 2005, consta subdividida nos tópicos "Histórico e estrutura", "Classes básicas; tabelas auxiliares; índice", "Síntese de notação", que está segmentada em dois tópicos "2.3.1 Com as tabelas auxiliares" e "2.3.2 Entre as classes principais". Esta estrutura era semelhante àquela utilizada para abordar a CDU e a Colon Classification, e indicava um enfoque no instrumento, desvinculado do processo que este deveria contemplar.

O currículo atual, estabelecido em 2009, não trouxe grandes mudanças em relação às formas de discutir os conteúdos em comparação aos anos finais da década de 2000, sendo a principal mudança a alteração da ordem de disciplinas: conteúdos de representação temática passaram a ser ministrados antes de serem apresentados os conteúdos de representação descritiva que permitem a identificação do documento em análise. Quanto à questão em discussão neste artigo, os conteúdos foram redimensionados em torno de instrumentos, fragilizando a abordagem articulada entre ordenação de documentos, classificação e catalogação. A organização da informação em sentido amplo passou a ser abordada na disciplina "Fundamentos da Organização da Informação", ofertada aos alunos que iniciam o curso. A classificação passou a ser trabalhada no âmbito das disciplinas "Sistemas de Classificação: CDD" e "Sistemas de Classificação: CDU". Já a catalogação passou a ser contemplada na disciplina "Catalogação Descritiva". 
A ordenação de documentos como conteúdo curricular no curso de graduação em Biblioteconomia da UFMG e relato de proposta de disciplina
Camila Mariana Aparecida da Silva; Matheus Aguiar de Carvalho; Gabriella Braga Andrade Martin; Cristina Dotta Ortega

Nos programas de 2018, a disciplina "Fundamentos da Organização da informação", embora não mencionasse a ordenação de documentos em sua ementa, discriminava esse processo como tópico final do programa e se propunha a discutir "A ordenação como proposta de leitura de uma coleção e o papel do método classificatório". Isto indica que as relações entre a ordenação em sentido amplo e a classificação foram contempladas, mesmo que a abordagem ocorra de forma horizontal, haja vista a proposta da disciplina em discutir apenas aspectos fundamentais da organização da informação.

As ementas das disciplinas "Sistemas de Classificação: CDD" e "Sistemas de Classificação: CDU", assim como os programas analisados de 2018, apresentam uma organização de conteúdos que se assemelha às anteriores, nas quais era perceptível o enfoque no ensino do uso de instrumentos de classificação visando à habilitação para a construção de notações pormenorizadas. A ementa da disciplina "Sistemas de Classificação: CDD" está dividida em dois tópicos: "Sistemas de classificação bibliográfica: histórico, evolução" e "Classificação Decimal de Dewey" e a disciplina sobre CDU repete a mesma estrutura. Na descrição dos conteúdos do programa, os tópicos da ementa eram desdobrados em três unidades. A primeira delas referia-se à discussão sobre classificação e classificação bibliográfica, propondo uma síntese sobre o histórico da classificação, a teoria da classificação bibliográfica e os sistemas de classificação bibliográfica. Na segunda e terceira unidades, abordava-se de forma exclusiva a CDD, partindo da abordagem histórica e estrutural do instrumento para, na sequência, trabalhar sua aplicação por meio de exercícios práticos em que se fazia uso do instrumento para formação de notações classificatórias. De igual modo, na disciplina "Sistemas de Classificação: CDU", a proposta disciplinar estava dividida em unidades que buscavam contemplar o "Histórico e evolução dos sistemas de classificação bibliográficos" seguido de uma discussão quanto aos "Fundamentos teóricos, características e funções da CDU" para, na sequência trabalhar a "Aplicação prática da CDU" por meio da realização de exercícios. Assim, as duas disciplinas em que a classificação bibliográfica é abordada possuem foco nos instrumentos de classificação bibliográfica e tratam, duplamente, do conteúdo "Histórico e evolução dos sistemas de classificação bibliográficos".

Quanto à disciplina "Catalogação Descritiva", no que concerne à ordenação de documentos, as "Tabelas de autor" são mencionadas na ementa sem articulação com outros itens. No programa de 2018 da disciplina, a relação de conteúdos propostos apresenta "Tabelas de autor", em conjunto a "Controle de autoridade e de assuntos", sob o tópico "Pontos de acesso". Contudo, dentre as referências listadas na bibliografia, não há nenhuma relacionada especificamente às tabelas de 
A ordenação de documentos como conteúdo curricular no curso de graduação em Biblioteconomia da UFMG e relato de proposta de disciplina
Camila Mariana Aparecida da Silva; Matheus Aguiar de Carvalho; Gabriella Braga Andrade Martin; Cristina Dotta Ortega

autor e, na seção "Sites de interesse", o link que remeteria à "Tabela de Cutter", encontrava-se indisponível em 2019 quando consultado.

Buscando sistematizar o percurso apresentado, o quadro abaixo apresenta o caminho disciplinar da ordenação de documentos nos currículos do curso de graduação em Biblioteconomia da UFMG. Em síntese, identificou-se perda da especificidade dos conteúdos referentes à ordenação de documentos nos currículos desde a década de 1950 até meados da década de 1970, período em que a amplitude do processo era evidenciada, assim como a diversidade de soluções para sua efetivação em sistemas de informação. Gradativamente, a discussão sobre a ordenação de documentos foi se tornando mais restritiva: de um processo (ordenação de documentos) a um único modelo (número de chamada) e deste a partes isoladas que não permitem compor sua estrutura por completo; de fato, ordenação de documentos e número de chamada são sequer mencionados.

Quadro 1: Disciplinas que tratam de conteúdos relacionados à ordenação de documentos nos currículos do curso de graduação em Biblioteconomia da $\mathrm{ECl} /$ UFMG de 1950 até os dias atuais.

\begin{tabular}{|l|l|}
\hline $\begin{array}{l}\text { Intervalo de anos e duração do } \\
\text { curso }\end{array}$ & $\begin{array}{l}\text { Disciplinas obrigatórias que abarcam a } \\
\text { ordenação de documentos }\end{array}$ \\
\hline $1950-1952$ (1 ano) & Classificação \\
\hline $1953-1956$ (2 anos) & Classificação I, II \\
\hline $1957-1961$ (3 anos) & Classificação I II, III \\
\hline $1962-1964$ (3 anos) & Classificação I, II, III \\
\hline $1964-1968$ (3 anos) & Classificação I, II, III \\
\hline $1968-1974$ (3 anos) & Classificação I, II \\
\hline $1975-1984$ (3 anos) & Classificação e Catalogação \\
\hline $\begin{array}{l}\text { Currículo de 1985 e ajustes } \\
\text { implantados em 1990 (4 anos) }\end{array}$ & Tratamento da Informação I \\
Teoria da Classificação e Indexação \\
\hline Currículo de 1998 (4 anos) & Tratamento da Informação II \\
\hline Currículo de 2009 (4 anos) & Tratamento da Informação IV \\
\hline
\end{tabular}


Sistemas de Classificação: CDU

Fonte: reformulado a partir de Ortega (2013, p. 193-194).

O apagamento da ordenação de documentos, imposto pelas sucessivas versões curriculares, contou com movimento de instrumentalização que se manifesta claramente nos nomes de disciplinas da última versão curricular, como "Sistemas de classificação: CDD" e "Sistemas de classificação: CDU". A instrumentalização, por sua vez, ocorreu por meio do abandono da consideração das relações entre os diversos processos de organização da informação, haja vista o significado da ordenação no contexto das clássicas catalogação e classificação. Frente a isso, a atividade docente traz dificuldade aos estudantes no estabelecimento de elos entre os conteúdos de organização da informação para a constituição de sistemas, assim como para uma compreensão integral da área.

Os problemas identificados vão ao encontro dos apontamentos feitos por Marysia Fiuza em texto escrito no ano de 1985. Ao refletir sobre sua prática docente no ensino da disciplina "Catalogação de assunto", também no curso de graduação em Biblioteconomia da UFMG, a autora argumentava que lhe parecia bastante problemático, o fato de que raramente se discutia o propósito de uso dos sistemas de classificação. Fiuza colocava em questão a finalidade dos sistemas de classificação bibliográfica, afirmando com convicção que se tratava do arranjo de livros nas estantes, atividade que não se confunde com a atribuição de assuntos diversos a eles, tratando também da necessidade de "discussão sobre os elementos do número de chamada e uso dos seus recursos, quando necessário, para a identificação de cada livro da coleção" (FIUZA, 1985, p. 266). Assim, infere-se que, para Fiuza, os sistemas de classificação bibliográfica precisam ser trabalhados em correlação à ordenação. Ela também trata da distinção entre classificação e indexação que, como foi abordado anteriormente, era um problema no currículo do curso àquele momento. Considerando a atualidade da problematização realizada pela autora na década de 1980, observamos que ela caminha na direção do argumento de que os conteúdos de organização da informação, posto que são fundamentais na estruturação de sistemas de informação de informação bibliográfica, precisam ser trabalhados de modo coeso.

\section{Relato de experiência: oferta de disciplinas optativas no curso de graduação em Biblioteconomia da UFMG}

A fim de suprir a lacuna relativa à ordenação de documentos na proposta curricular vigente e contribuir para uma compreensão integrada da construção teórica do processo, de suas metodologias e dos 
A ordenação de documentos como conteúdo curricular no curso de graduação em Biblioteconomia da UFMG e relato de proposta de disciplina
Camila Mariana Aparecida da Silva; Matheus Aguiar de Carvalho; Gabriella Braga Andrade Martin; Cristina Dotta Ortega

instrumentos associados, buscou-se uma alternativa temporária expressa na elaboração e oferta de disciplinas optativas referentes à temática. Paralelamente, integrando as atividades da Semana do Bibliotecário promovidas pela Biblioteca Professora Etelvina Lima, da Escola de Ciência da Informação da UFMG, foram ministradas duas oficinas sobre elaboração do número de chamada, nas quais o público era composto majoritariamente por alunos do curso de graduação em Biblioteconomia.

A oferta de disciplinas ocorreu como atividade de Estágio Docente para discentes bolsistas CAPES em nível de doutorado, no Programa de Pós-Graduação em Ciência da Informação (PPGCl) da ECl - UFMG, no contexto de participação no Programa de Incentivo à Formação Docente (PIFD) da Pró-Reitoria de Graduação da UFMG, e paralelamente às atividades de pesquisa sobre o tema. Deste modo, a disciplina optativa de 30 horas intitulada "Número de chamada: histórico, funções e construção" foi ministrada duas vezes, no segundo semestre de 2017 e primeiro semestre de 2018; após reestruturação, no segundo semestre de 2018, foi ofertada disciplina de 60 horas sob o título "Ordenação de documentos e número de chamada: historicidade, função e propostas".

Esta revisão pautou-se pela análise curricular desenvolvida no tópico anterior, pela experiência docente e pela apreciação discente das disciplinas ofertadas nos semestres precedentes mas, também, devido ao entendimento de que era possível e desejável aprimorar as estratégias didáticas a fim de aprofundar a aprendizagem como processo de significação e construção de autonomia para produção de conhecimentos.

A explanação que segue tem como base a experiência resultante da última oferta e que foi norteada pela seguinte ementa:

Ordenação no contexto dos processos de Organização da Informação e sua relação com a catalogação descritiva e a classificação bibliográfica. Métodos de ordenação em articulação aos arranjos estruturados na observância dos objetivos institucionais, público e características da coleção. Modelos voltados à ordenação de documentos em perspectiva bibliográfica: estrutura, historicidade e funções. Número de chamada enquanto modelo voltado à ordenação de documentos. Atividades de capacitação para elaboração de soluções baseadas em diferentes propostas de uso do número de chamada (SILVA; ORTEGA, 2018a).

Assim, a proposta executada visava criar possibilidade de discutir a ordenação de documentos como atividade de organização da informação a ser abordada com enfoque no número de chamada, mas não restrita a ele. Buscou-se, portanto, ultrapassar exclusivamente a capacitação para a 
A ordenação de documentos como conteúdo curricular no curso de graduação em Biblioteconomia da UFMG e relato de proposta de disciplina
Camila Mariana Aparecida da Silva; Matheus Aguiar de Carvalho; Gabriella Braga Andrade Martin; Cristina Dotta Ortega

elaboração deste modelo, visando construir a compreensão acerca das funcionalidades que a ordenação de documentos exerce e dos condicionantes que permeiam a escolha de soluções. Para tanto, fez-se fundamental o trabalho com os conceitos relativos à catalogação, classificação e ordenação, reforçando suas especificidades, mas, sobretudo, a interlocução que eles precisam estabelecer na estruturação de sistemas de informação consistentes e orientados ao usuário.

A disciplina foi operacionalizada em dois módulos: o conceitualhistórico e o instrumental, como é possível observar no esquema a seguir:

Figura 1: Estruturação da disciplina "Ordenação de documentos e número de chamada: historicidade, função e propostas"

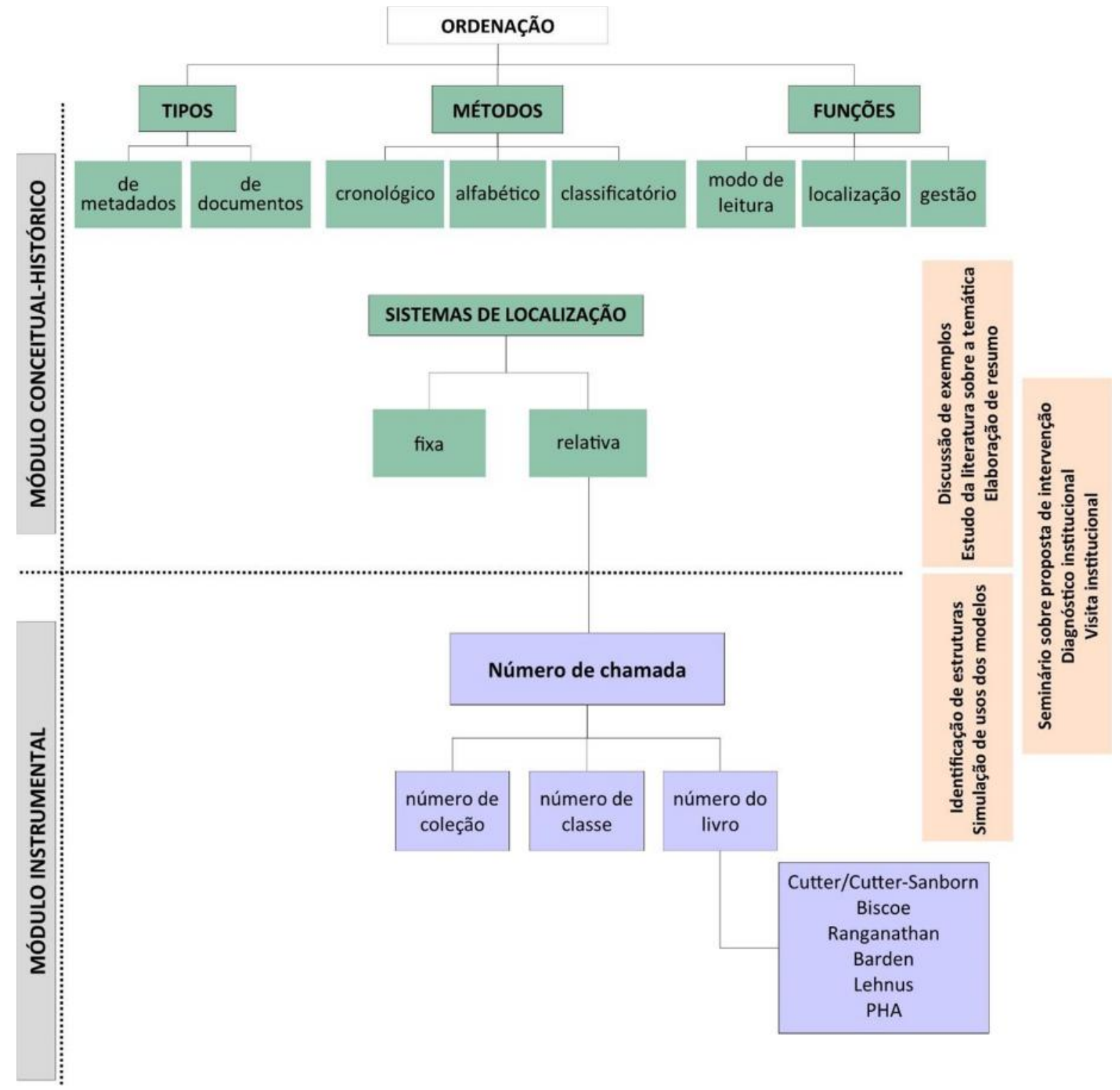

Fonte: elaborado pelos autores (2019). 
A ordenação de documentos como conteúdo curricular no curso de graduação em Biblioteconomia da UFMG e relato de proposta de disciplina
Camila Mariana Aparecida da Silva; Matheus Aguiar de Carvalho; Gabriella Braga Andrade Martin; Cristina Dotta Ortega

O módulo conceitual-histórico foi assim denominado por se entender que didaticamente a construção da compreensão conceitual deveria preceder a abordagem histórica, pois permitiria interpelar com mais clareza e maleabilidade, o percurso e as modificações que caracterizam a ordenação de documentos ao longo do tempo. Partindo desta concepção, a disciplina pautou-se pela premissa de que atividades de organização da informação são desenvolvidas na observância de três elementos basilares: os objetivos institucionais, o público em questão e as características dos documentos. Ainda que o objetivo primordial da primeira etapa deste módulo tenha sido a caracterização da ordenação a partir de suas funções, tipos e métodos, a apresentação de exemplos foi elemento-chave para a construção de entendimento quanto à sua generalidade e elementos condicionantes. Assim, bibliografias, sites de instituições, catálogos online e soluções concretas de ordenação de documentos foram amplamente empregados como recurso didático de explicitação da distinção entre ordenação de metadados e ordenação de documentos, além dos métodos cronológico, alfabético e classificatório.

Seguindo um padrão similar ao identificado nos semestres anteriores, houve considerável resistência por parte dos alunos em aderir à proposta inicial de reflexão sem imediata aplicação dos conteúdos trabalhados. Antes de pensar o processo em questão, de considerar as especificidades que o caracterizam e experimentar testá-lo em suas potencialidades, havia uma ânsia por parte dos alunos em aprender uma forma idealmente correta e universal de colocar em prática o uso de instrumentos sob a justificativa de que o mercado demandaria habilidades desta ordem. Todavia, como ressalta Rodrigues (2003, p. 366), não cabe à formação universitária limitar-se exclusivamente à habilitação do aluno para o exercício de uma profissão, "[...] por meio da repetição mecânica do conhecimento já existente, como se fosse suficiente para lançá-lo ao mundo do trabalho." Neste sentido, tornou-se estratégico abordar os modelos escolhidos a partir de um viés reflexivo, de modo a favorecer o aprimoramento das habilidades analíticas e estimular a criatividade e a construção da autonomia, fundamentais ao percurso universitário. Ademais, insistir no pilar exclusivamente instrumental seria afirmar, equivocadamente, um exercício profissional estereotipado que não demanda maleabilidade e inventividade nas intervenções.

Este primeiro recorte estabelecido para a disciplina foi sistematizado pelos discentes em uma atividade de resumo baseada em trecho relativo ao primeiro capítulo do livro "Ordenação de documentos na atividade bibliotecária" (ORTEGA; SILVA; SANTOS, 2016). A demanda por elaboração textual própria a partir de compreensão norteada pelo excerto permitiu verificar a compreensão discente quanto aos conceitos abordados e subsidiou a continuidade da disciplina no que se refere aos conteúdos 
A ordenação de documentos como conteúdo curricular no curso de graduação em Biblioteconomia da UFMG e relato de proposta de disciplina
Camila Mariana Aparecida da Silva; Matheus Aguiar de Carvalho; Gabriella Braga Andrade Martin; Cristina Dotta Ortega

que ainda careciam de melhor compreensão. Após esta contextualização da ordenação em abordagem ampla, foi possível dar início à discussão sobre a ordenação de documentos em suas especificidades. Com o enfoque nos sistemas de localização fixa e relativa, passou-se à discussão do histórico da atividade, especialmente a partir do século XIX, com a implantação do acesso aberto às coleções, e, consequentemente, a sistematização dos debates e propostas para o número de chamada. Nesta etapa, além de arranjos sustentados em sistemas de localização fixa (como os casos da Biblioteca Nacional brasileira e do Real Gabinete Português de Leitura), foi enfatizada a estrutura tripartite do número de chamada (número de coleção, número de classe e número do livro) e a função particular atribuída a cada um de seus elementos.

Com o intuito de demarcar a transição do primeiro módulo da disciplina para o segundo e retomar noções cuja compreensão ainda parecia frágil, foi demandado aos alunos que se reunissem em duplas e respondessem a algumas questões tendo por base um excerto retirado do livro de Lentino (1971) "Guia teórico, prático e comparado dos sistemas de classificação bibliográfica". No trecho escolhido, a autora discorre sobre alguns pontos referentes à ordenação de documentos e mais especificamente sobre a suposta superioridade do método classificatório em relação aos demais. Contudo, a resolução proposta pelos alunos apresentava problemas concernentes à compreensão e análise do texto que precisaram ser revistos e rediscutidos, como segue.

A fim de atenuar os problemas identificados e reelaborar entendimentos, o excerto-base para a atividade foi projetado em sala e lido em voz alta paulatinamente. A cada parágrafo lido, foi pedido aos alunos que apresentassem frases curtas ou palavras que sintetizassem as ideias trabalhadas e estas observações foram anotadas lateralmente ao texto projetado. Terminada a leitura e escritos os apontamentos feitos pelos alunos, foi possível construir um entendimento global do texto, retomar as questões da atividade e construir conjuntamente a reflexão pedida. Os alunos conseguiram compreender o argumento central e a concepção de ordenação de documentos trabalhada pelo texto.

Ao fim da atividade, eles ressaltaram três pontos: 1. a precipitação na entrega da atividade teria atrapalhado sua execução; 2. a leitura de textos é feita por eles sem o hábito de tentar compreender a argumentação desenvolvida, buscando, exclusivamente, captar o assunto geral que está sendo abordado; e 3. a retomada do trecho com a leitura e resolução conjunta auxiliou na consolidação do entendimento dos conceitos que estavam sendo trabalhados na disciplina e, consequentemente, na percepção mais acurada dos elementos apresentados pelo excerto. Houve participação intensiva na realização da atividade e os alunos fizeram vários apontamentos pertinentes, 
A ordenação de documentos como conteúdo curricular no curso de graduação em Biblioteconomia da UFMG e relato de proposta de disciplina
Camila Mariana Aparecida da Silva; Matheus Aguiar de Carvalho; Gabriella Braga Andrade Martin; Cristina Dotta Ortega

estabelecendo, em grande medida, diálogo direto entre eles mesmos, impulsionando a atuação docente como mecanismo de articulação e contraponto entre as diferentes falas que dialogaram com o texto.

Esta atividade explicitou o ponto crítico da disciplina: a dificuldade dos alunos em identificar, compreender e distinguir as funções, instrumentos, produtos e contextos de aplicabilidade associados às atividades de organização da informação, especialmente a diferenciação entre classificação e indexação. A dificuldade foi explicitada nos três semestres de trabalho e mostrou-se ainda mais intensamente quando a análise de assunto como operação para a atividade de indexação, conforme presente no currículo da graduação, foi mencionada nas discussões. Os alunos afirmaram confundir-se quanto à aplicabilidade da análise de assunto e demonstraram dificuldade acentuada na leitura e compreensão textual para fins de estudo, tomando a primeira pela segunda. Cabe, portanto, pontuar que, se não há clareza, no currículo, quanto à finalidade da classificação bibliográfica para fins de ordenação em relação à análise de assunto para fins de indexação, este tipo de análise mostrou-se também indistinto, neste caso, da leitura para fins de estudo. Ademais, foi possível identificar a dificuldade dos alunos em conferir relevância a outros instrumentos de classificação bibliográfica que não a CDD ou a CDU e em perceber a pertinência de usos não literais ou localmente adaptados destes sistemas.

No módulo instrumental, optou-se por enfatizar a composição do número do livro, uma vez que o número de coleção é elemento opcional da estrutura e o número de classe seria contemplado, conforme a configuração curricular, no âmbito das disciplinas "Sistemas de Classificação: CDD" e "Sistemas de Classificação: CDU", embora não sob o enfoque da ordenação. Ainda assim, foram enfatizadas questões relativas à necessidade de compatibilidade, coerência e economia na conjugação entre o número de classe elaborado e as estratégias de formulação do número do livro. Diferentes modelos foram trabalhados na disciplina (Cutter, Biscoe, Barden, Lehnus, PHA) e para cada um deles foi proposta uma atividade. O número do livro baseado em critérios alfabéticos foi enfatizado e buscou-se construir compreensão sobre a composição das tabelas de autor, sendo apresentados aplicativos para geração automática das notações.

A cada aula, norteados pelo modelo em questão, os alunos eram incitados a elaborar uma proposta de ordenação para um conjunto de documentos previamente selecionados. Deste modo, tornava-se possível simular a elaboração de números de chamada para coleções e discutir a limitação, expansividade e adaptabilidade de cada proposta. Ademais, esta opção mostrou-se especialmente adequada para o módulo instrumental, pois incitou os alunos a compartilharem suas vivências como 
A ordenação de documentos como conteúdo curricular no curso de graduação em Biblioteconomia da UFMG e relato de proposta de disciplina
Camila Mariana Aparecida da Silva; Matheus Aguiar de Carvalho; Gabriella Braga Andrade Martin; Cristina Dotta Ortega

usuários e como estagiários, interpelando os arranjos propostos institucionalmente, ao buscar compreender as estratégias empregadas, suas possíveis vinculações teóricas em termos de aproximação aos modelos discutidos em sala e sua adequação no que concerne aos contextos em questão.

Paralelamente ao desenvolvimento do módulo instrumental, os alunos elaboraram o trabalho final da disciplina. Este trabalho consistia no diagnóstico, análise e proposta de intervenção para uma coleção de documentos ordenados por meio do número de chamada. Os discentes deveriam escolher uma instituição, descrevê-la quanto à missão, tipos de coleções abarcadas e perfil dos usuários, para, então, escolher uma das coleções e nela selecionar 10 itens dentro de uma mesma classe para decompor e explicitar as estratégias empregadas na elaboração do número de chamada. Assim, apoiado na caracterização da instituição, da coleção e de seu público, o aluno era convidado a identificar inconsistências ou pontos passíveis de aprimoramento na proposta de ordenação de documentos implementada, podendo indicá-los e propor alternativas com o intuito de mitigá-los.

Por se tratar de trabalho extenso e complexo em função da articulação de elementos conceituais e da distinção entre métodos, instrumentos e produtos, além da proposta de intervenção, houve encontro com as duplas discentes para discussão da versão preliminar do trabalho. Este momento particular de orientação mostrou-se fundamental para dirimir dúvidas, aprofundar elementos pouco explorados, adensar a análise realizada e oferecer orientação sobre os modos de redação, os artifícios para apresentação dos dados coletados e a composição analítica do trabalho como um todo coerente e articulado.

Portanto, alinhada à perspectiva de Masetto (2003, p. 117-118), este trabalho se norteou pela abordagem do ensino com pesquisa em que os alunos foram incitados a:

- tomar iniciativa na busca de informações, dados e materiais necessários para o estudo; [...]

- selecionar, organizar, comparar, analisar, correlacionar dados e informações;

- fazer inferências segundo dados e informações, levantar hipóteses, checá-las, comprová-las, reformulá-las e tirar conclusões;

- elaborar um relatório com características científicas;

- comunicar os resultados obtidos com clareza, ordem, precisão científica, oralmente e por escrito.

O desenvolvimento gradativo do trabalho final parece ter contribuído para a realização de duas outras atividades que constituíram a disciplina: um seminário baseado no artigo "Uma nova proposta de classificação de histórias em quadrinhos" (PAJEÚ et al., 2007) - selecionado por descrever 
A ordenação de documentos como conteúdo curricular no curso de graduação em Biblioteconomia da UFMG e relato de proposta de disciplina
Camila Mariana Aparecida da Silva; Matheus Aguiar de Carvalho; Gabriella Braga Andrade Martin; Cristina Dotta Ortega

detalhadamente os elementos constituintes de uma nova proposta de arranjo para uma coleção de histórias em quadrinhos, e uma visita institucional à Divisão de Obras Raras da UFMG - escolhida em função da diversidade de coleções que abriga, dos arranjos que materializa e dos desafios no que concerne à gestão do espaço. Em ambas as atividades, os alunos demonstraram compreensão analítica que possibilitou o reconhecimento e manipulação da estrutura do número de chamada e a apreciação de sua pertinência, funcionalidade e limitações, conforme o contexto em questão.

Ao final da disciplina, os alunos foram convidados a integrar uma roda de conversa que tinha por objetivo fazer uma avaliação coletiva do percurso vivenciado no semestre. Os discentes participantes afirmaram percepção sobre a pertinência da temática trabalhada para sua formação e frisaram haver demanda por mais disciplinas optativas que contemplem e aprofundem temáticas relacionadas à organização da informação. Eles também ressaltaram ter dificuldades para relacionar os conteúdos trabalhados pelas diferentes disciplinas, sendo complicado compreender, por exemplo, como a análise de assunto, a indexação e a classificação se relacionam e, ainda, como a catalogação se articula com elas. Frente a este quadro, argumentam que o curso lhes parece demasiado teórico; paradoxalmente, nossa avaliação é a de que há fragilidade dos construtos teóricos que permitiram embasar o estabelecimento de relações entre os processos, bem como os mecanismos para sua instrumentalização.

Os problemas identificados, tanto na elaboração das disciplinas ofertadas, quanto em seu desenvolvimento ao longo de três semestres, corroboram a percepção quanto à dispersão e pequena interlocução dos conteúdos obrigatórios de organização da informação constantes no currículo de graduação. Neste sentido, a intervenção, entendida como uma interferência propositadamente realizada, parece ter sido exitosa pois, como afirma Rodrigues (2003), ela foi ao encontro das necessidades dos alunos que atribuíram valor e relevância para seu processo formativo. Esse valor foi reafirmado quando os próprios alunos, depois de entregarem o trabalho final, demandaram a socialização de todos os trabalhos finais sob a justificativa de que suas análises pareciam pertinentes e que, da mesma forma, gostariam de tomar conhecimento do percurso e das escolhas realizadas na elaboração dos trabalhos dos colegas.

A oportunidade de ouvir dos alunos uma avaliação positiva sobre os objetivos da disciplina no fim de semestre corroborou a percepção de que - modo de estruturação da disciplina e as estratégias didáticas empregadas mostraram-se eficazes. As variações de técnicas e recursos norteadas pelos objetivos de aprendizagem explicitados a cada atividade em questão, além da possibilidade de reformulá-los quando da 
A ordenação de documentos como conteúdo curricular no curso de graduação em Biblioteconomia da UFMG e relato de proposta de disciplina
Camila Mariana Aparecida da Silva; Matheus Aguiar de Carvalho; Gabriella Braga Andrade Martin; Cristina Dotta Ortega

constatação de incongruências ou falta de adesão discente, parecem ter sido os elementos decisivos para manter o nível de motivação e autopercepção de progresso por parte dos alunos. Assim, o desenvolvimento da proposta de intervenção suscitada pela identificação da lacuna explicitada no currículo mostrou-se particularmente profícua, considerando-se o contexto em questão e os resultados alcançados.

\section{Considerações finais}

A progressiva perda de espaço da atividade de ordenação de documentos como conteúdo associado ao ensino da organização da informação, na Escola de Ciência da Informação da UFMG, deve ser avaliada, uma vez que não apenas a atividade continua sendo desenvolvida em sistemas diversos, como o número de chamada ainda é modelo referencial no âmbito de bibliotecas que facultam livre acesso às estantes. $\mathrm{Na}$ trajetória curricular analisada, enquanto conteúdo compreensível por meio de métodos que implicam propostas de comunicação, bem como em modos de gestão e acesso, a ordenação de documentos foi progressivamente tornando-se restrita ao número de chamada, entendido como resposta à atividade, mas não enquanto modelo dotado de historicidade e de estrutura própria manipulável e, portanto, adaptável. Na estrutura curricular atual, o próprio número de chamada não é abordado como produto complexo e articulado que ultrapassa a junção automática entre notações de classe compostas a partir da CDD ou da CDU e as notações de autor elaboradas com base nas tabelas de Cutter. A ênfase ao ensino dos sistemas de classificação bibliográfica mencionados, dissociada de uma reflexão explícita e sistemática quanto à sua funcionalidade, reforça compreensão reducionista que restringe o uso destes instrumentos a notações pouco efetivas quanto a seu papel na elaboração de números de chamada. Ademais, desconsidera-se que a espacialização das coleções compõe uma proposta de sentido e recurso de acesso aos documentos com fins mediadores.

Cabe considerar ainda que, mesmo não sendo tópico com vasta literatura associada ou com abordagem didática estruturada, o tema da ordenação de documentos já foi explorado de modo consistente e propositivo em termos das generalizações e abstrações que competem à formação em nível superior. Os conteúdos propostos nas disciplinas até meados da década de 1970 atestam este fato, não pelo mero resgate do passado, sob viés saudosista e conservador, mas, antes, pela explicitação dos objetivos, métodos e diferentes formas de interpelação à ordenação de documentos que puderam ser observados. Busca-se enfatizar que as questões discutidas pela área precisam estar em consonância com as demandas atuais, mas que a compreensão destas se faz, também, 
A ordenação de documentos como conteúdo curricular no curso de graduação em Biblioteconomia da UFMG e relato de proposta de disciplina
Camila Mariana Aparecida da Silva; Matheus Aguiar de Carvalho; Gabriella Braga Andrade Martin; Cristina Dotta Ortega

mediante a observação e entendimento da historicidade e fundamentação conceitual já alcançadas.

A variabilidade disciplinar constatada na análise curricular é avaliada aqui como cenário em que estiveram ausentes, propostas orientadas ao favorecimento de uma compreensão globalizante e articulada dos diversos conteúdos pertinentes à organização da informação. Mais que isso, entende-se que a ordenação de metadados poderia ser melhor explorada, tanto nas discussões que compreendem a elaboração de catálogos e bibliografias, quanto no que concerne à realização da atividade no ambiente digital. Este ponto parece relevante, posto que coloca como demanda de pesquisa e ensino uma reflexão mais sistemática e consistente em termos conceituais sobre a ordenação na historicidade de suas práticas, assim como em sua generalidade e especificidades, haja vista os desafios que se colocam para os docentes, pesquisadores e profissionais da informação diante da crescente presença das coleções em ambiente web.

Deste modo, faz-se necessário a identificação, elaboração e organização dos conteúdos para que, então, se opere sua transposição didática. Esta transposição implica compreensão articulada da temática que permita contextualizá-la conforme as demandas sócio-políticas consideradas para a construção de uma estrutura curricular pertinente.

\section{Referências}

ASSUNÇÃO, J. B. de; FIUZA, M. M. Reformulação do currículo do Curso da escola de Biblioteconomia da UFMG. Revista da Escola de Biblioteconomia da UFMG, Belo Horizonte, v. 3, n. 2, p. 218-233, set. 1974.

BARBOSA, A. P. Teoria e prática dos sistemas de classificação bibliográfica. Rio de Janeiro: IBICT, 1969.

CARIBÉ, R. de C. do V. Notação de autor: sua história. Informação \& Sociedade, João Pessoa, v. 26, n. 2 p. 121-135, maio/ago. 2016.

Disponível em: https://periodicos.ufpb.br/ojs2/index.php/ies/article/view/28650/16207. Acesso em: 02 out. 2019.

CARIBÉ, R. de C. do V. Ordenamento de documentos em bibliotecas: tipologia. Informação \& Sociedade, J oão Pessoa, v. 29, n. 2, p. 125-144, abr./jun. 2019. Disponível em:

https://periodicos.ufpb.br/ojs2/index.php/ies/article/view/44307/pdf. Acesso em: 02 out. 2019.

CELLARD, A. A análise documental. In: POUPART, J. A pesquisa qualitativa: enfoques epistemológicos e metodológicos. Petrópolis: Vozes, 2014. p. 295-316. 
A ordenação de documentos como conteúdo curricular no curso de graduação em Biblioteconomia da UFMG e relato de proposta de disciplina
Camila Mariana Aparecida da Silva; Matheus Aguiar de Carvalho; Gabriella Braga Andrade Martin; Cristina Dotta Ortega

CESARINO, M. A. da N.; VIANNA, M. M. O Curso de Graduação em Biblioteconomia da UFMG. Revista da Escola de Biblioteconomia da UFMG, Belo Horizonte, v. 19, n. especial, p. 37-67, mar. 1990. Disponível em: http://hdl.handle.net/20.500.11959/brapci/73181. Acesso em: 02 out. 2019.

CUTTER, C. A. Explanation of the alphabetic-order marks (three-figure tables). Northampton: Herald J ob Print, 1908.

CUTTER, C. A.; SANBORN, K. Explanação das marcas de autor CutterSanborn: tabelas com três algarismos. 2. ed. Rio de Janeiro: Departamento de Imprensa Oficial, 1962.

DAMI ANI, M. F. Sobre pesquisas do tipo intervenção In: Encontro Nacional de Didática e Prática de Ensino, 16., 2012, Campinas. Anais [...]. Campinas: UNICAMP, 2012. p. 1-9. Painel: AS PESQUISAS DO TIPO INTERVENÇÃO E SUA I MPORTÂNCIA PARA A PRODUÇÃO DE TEORIA EDUCACI ONAL. Disponível em: http://endipe.pro.br/ebooks-2012/2345b.pdf. Acesso: em 02 out. 2019.

DAMIANI, M. F. et al. Discutindo as pesquisas do tipo intervenção pedagógica. Cadernos de Educação, Pelotas, n. 45, p. 57-67, maio/ago. 2013. Disponível em:

https://periodicos.ufpel.edu.br/ojs2/index.php/caduc/article/view/3822. Acesso em: 02 out. 2019.

FIUZA, M. M. O ensino da "catalogação de assunto". Revista da Escola de Biblioteconomia da UFMG, Belo Horizonte, v. 14, n. 2, p. 257-269, set. 1985. Disponível em: http://www.brapci.inf.br/index.php/article/download/13784. Acesso em: 02 out. 2019.

JOUGUELET, S. Classement. In: CACALY, S. (Coord.). Dictionnaire encyclopédique de l'information et de la documentation. Paris: Nathan, 1997. p. 135-136.

LEHNUS, D. J. Notação de autor: manual para bibliotecas. Rio de Janeiro: BNG/Brasilart, 1978.

LENTINO, N. Guia teórico, prático e comparado dos sistemas de classificação bibliográfica. São Paulo: Polígono, 1971.

MANN, M. Catalogação e classificação de livros. Rio de Janeiro: Fundo de Cultura, 1962.

MASETTO, M. T. Técnicas para o desenvolvimento da aprendizagem em aula. In: MASETTO, M. T. Competência pedagógica do professor universitário. São Paulo: Summus, 2003. cap. 8, p. 97-157. 
A ordenação de documentos como conteúdo curricular no curso de graduação em Biblioteconomia da UFMG e relato de proposta de disciplina
Camila Mariana Aparecida da Silva; Matheus Aguiar de Carvalho; Gabriella Braga Andrade Martin; Cristina Dotta Ortega

MEY, E. S. A. Introdução à catalogação. Brasília: Briquet de Lemos, 1995. MEY, E. S. A.; SILVEIRA, N. C. Catalogação no plural. Brasília: Briquet de Lemos, 2009.

ORTEGA, C. D. Contexto de desenvolvimento da Organização da Informação, com enfoque para a Catalogação, na Escola de Ciência da Informação da UFMG. Perspectivas em Ciência da Informação, Belo Horizonte, v. 18, n. 2, p. 182-215, abr./jun. 2013. Disponível em: http://portaldeperiodicos.eci.ufmg.br/index.php/pci/article/view/1805/1181. Aceso em: 02 out. 2019.

ORTEGA, C. D. Ordenação de documentos: fundamentos e relações com a classificação bibliográfica. In: GUI MARÃES, J. A. C.; DODEBEI, V. (Org.). Organização do conhecimento e diversidade cultural. Marília: ISKO Brasil; FUNDEPE, 2015. v. 3, p. 765-797. Disponível em: http://isko-brasil.org.br/wpcontent/uploads/2013/02/livro-ISKO-2017.pdf. Acesso em: 02 out. 2019.

ORTEGA, C. D.; SILVA, C. M. A. da. A ordenação de documentos como atividade de organização da informação: proposta de fundamentação e atualização. In: ENCONTRO IBÉRICO EDICIC, 6., 2013, Porto. Anais [...]. Porto: Centro de Estudos das Tecnologias e Ciências da Comunicação, Faculdade de Letras da Universidade do Porto; León: Universidad de Léon, 2013. p. 1618-1635. Disponível em: http://www.youblisher.com/p/745142-VIEncontro-Iberico-EDICIC-2013-Globalizacao-Ciencia-Informacao/. Acesso em: 02 out. 2019.

ORTEGA, C. D.; SILVA, C. M. A. da; SANTOS, M. N. dos. A ordenação de documentos na atividade bibliotecária. Brasília: Briquet de Lemos, 2016. Disponível em: https://archive.org/details/OrdenaoDeDocumentosNaAtividadeBibliotecria. Acesso em: 02 out. 2019.

PAJEÚ et al. Uma nova proposta de classificação de histórias em quadrinhos. Biblionline, J oão Pessoa, v. 3, n. 2, jul./dez. 2007. Disponível em: https://periodicos.ufpb.br/ojs2/index.php/biblio/article/view/1920/1689. Acesso em: 02 out. 2019.

PINHEIRO, A. V. T. da P. A ordem dos livros na biblioteca: uma abordagem preliminar ao sistema de localização fixa. Rio de Janeiro: Interciência; Niterói: Intertexto, 2007.

PRADO, H. de A. Tabela 'PHA': para individualizar os autores dentro das diversas classes de assunto, isto é, dentro dos mesmos números de classificação. 3. ed. São Paulo: T. A. Queiroz, 1984. 
A ordenação de documentos como conteúdo curricular no curso de graduação em Biblioteconomia da UFMG e relato de proposta de disciplina
Camila Mariana Aparecida da Silva; Matheus Aguiar de Carvalho; Gabriella Braga Andrade Martin; Cristina Dotta Ortega

RANGANATHAN, S. R. Prolegomena to Library Classification. 3 ed. New York: Asia Publishing House, 1967.

RODRIGUES, M. E. F. A pesquisa no ensino e o ensino da pesquisa. Transı nformação, Campinas, v. 15, n. 3, p. 363-372, set./dez. 2003. Disponível em: http://www.scielo.br/scielo.php?script=sci arttext\&pid=S151797022002000200005\&lng=en\&nrm=iso. Acesso em: 02 out. 2019.

SATIJA, M. P. Book number and call number. In: ENCYCLOPEDIA of library and information science. New York: Marcel Dekker, 1990. v. 45, p. 18-45. SILVA, C. M. A. da. Para uma abordagem contemporânea sobre ordenação de documentos: propostas do século XIX e início do XX. 2016. Dissertação (Mestrado em Ciência da Informação) - Escola de Ciência da Informação, Universidade Federal de Minas Gerais, Belo Horizonte, 2016. Disponível em: https://repositorio.ufmg.br/handle/1843/BUBD-AMWGPB. Acesso em: 02 out. 2019.

SILVA, C. M. A. da; ORTEGA, C. D. Das propostas que antecederam o número de chamada: a ordenação de documentos nos manuais francófonos de Biblioteconomia de meados do século XIX a 1930. In: PINHO, F. A.; GUIMARÃES, J. A. C. (org.). Memória, tecnologia e cultura na organização do conhecimento. Recife: Ed. UFPE, 2017a. v. 4. p. 15-25. Disponível em: http://hdl.handle.net/20.500.11959/brapci/121198. Acesso em: 02 out. 2019.

SILVA, C. M. A. da; ORTEGA, C. D. Proposals that preceded the call number: shelf arrangement in the francophone manuals of Librarianship from the mid-nineteenth century to 1930. Knowledge Organization, v. 44, n. 8, p. 605-614, 2017b.

SILVA, C. M. A. da; ORTEGA, C. D. Programa de disciplina Tópicos em Catalogação e Classificação da Informação D: Ordenação de documentos e número de chamada: historicidade, função e propostas. Curso de Biblioteconomia da Universidade Federal de Minas Gerais. ago. 2018a. Disponível em: http://colgradbiblio.eci.ufmg.br/o-curso/teste/2018-2/oti-099-ta2-top-emcatalog-e-classif-da-inform.pdf/view. Acesso em: 02 out. 2019.

SILVA, C. M. A. da; ORTEGA, C. D. A ordenação de documentos no curso de Biblioteconomia da UFMG: notas sobre um conteúdo quase esquecido. In: ENCONTRO NACIONAL DE PESQUISA EM CIÊNCIA DA INFORMAÇÃO, 19., 2018, Londrina. Anais [...]. Londrina: UEL, 2018b. p. 3846-3866. Disponível em: http://enancib.marilia.unesp.br/index.php/XIXENANCIB/xixenancib/paper/view/1062. Acesso em: 02 out. 2019. 
SILVA, C. M. A. da; TOLENTINO, V. de S. FRBRizando as coleções a partir do número de chamada: uma aproximação possível. In: SEMINÁRIO NACIONAL DE BIBLIOTECAS UNI VERSITÁRIAS, 20., 2018, Salvador. Anais [...]. Salvador: UFBA, 2018. p. 271-285. Disponível em:

http://repositorio.ufba.br/ri/handle/ri/27708. Acesso em: 02 out. 2019.

SILVA, C. M. A. da; TOLENTINO, V. S.; ORTEGA. C. D. Número de chamada e FRBR: um diálogo norteado por princípios da Organização da Informação. Transı nformação, Campinas, v. 31, p. 1-12, abr. 2019. Disponível em: http://www.scielo.br/scielo.php?script=sci arttext\&pid=S010337862019000100507\&lng=en\&nrm=iso. Acesso em: 02 out. 2019. VELLUCCI, S. L. Metadata. Annual Review of information Science and Technology (ARIST), Medford, v. 33, p. 187-222, 1998.

VERÓN, E. Espaces du livre: perception et usages de la classification et du classement en bibliothèque. Paris: BPI - Centre Georges-Pompidou, 1989. 